\title{
ELABORATION OF NEW METHOD OF DEEP PROCESSING OF CAROTENE-CONTAINING RAW MATERIALS INTO NANOADDITIVES WITH THE USE OF CRYOGENIC FREEZING AND FINE-DISPERSED GRINDING
}

\author{
Viktoriya Pogarska \\ Department of Technology processing of fruits, vegetables and milk \\ Kharkiv State University of Food Technology and Trade \\ 333 Klochkivska str., Kharkiv, Ukraine, 61051 \\ ktppom@ukr.net \\ Raisa Pavlyuk \\ Department of Technology processing of fruits, vegetables and milk \\ Kharkiv State University of Food Technology and Trade \\ 333 Klochkivska str., Kharkiv, Ukraine, 61051 \\ Nadiya Timofeyeva \\ Public utility company "Children's Food production facility» \\ 41-B Gagarina ave., Kharkiv, Ukraine, 61001 \\ kdp2010@yandex.ua

\section{Leonida Bilenko} \\ Deputy Director of Learning Support \\ Kharkiv Trade-Economic Colledge of Kyiv National University of Trade and Economics \\ 202 Klochkivskaya str., Kharkiv, Ukraine, 61045 \\ Leonida_Bilenko@list.ru \\ Tetyana Stukonozhenko \\ Department of Technology processing of fruits, vegetables and milk \\ Kharkiv State University of Food Technology and Trade \\ 333 Klochkivska str., Kharkiv, Ukraine, 61051
}

\footnotetext{
Abstract

The aim of the work is elaboration of principally new cryogenic method of deep processing of carotene-containing vegetable raw material (CCVRM) such as carrot, pumpkin, sweet Bulgarian pepper, tomato, sea buckthorn, apricot using cryogenic freezing and fine-dispersed grinding.

The new method of deep processing leads to more full extracting and removal of $\beta$-carotene from the state, bound with biopolymers into free and hydrophilic form. The mechanism of these processes was presented. It was established, that mass share of $\beta$-carotene in cryopuree, received by the new method, exceeds its content in initial (fresh) CCVRM in 3,0..3,5 times.

The regularities of growth and transformation of carotenoids separately at freezing with different high speeds and low-temperature grinding of CCYRM were established. It was demonstrated, that at cryogenic freezing take place quantitative increase of mass share of carotenoids in 2,0...2,5 times comparing with initial (fresh) raw material depending on freezing speed and type of CCVRM. That is it was demonstrated, that frozen carotene-containing vegetable raw material contains $2,0 \ldots .2,5$ times more $\beta$-carotene than fresh one. Mechanism of these processes was presented.

It was demonstrated, that cryopuree of CCVRM, received using new methods of deep processing, exceeds the initial (fresh) raw material by the content not only $\beta$-carotene but also other low-molecular bioactive substances: L-ascorbic acid - in 2,0...2,2 times, phenol

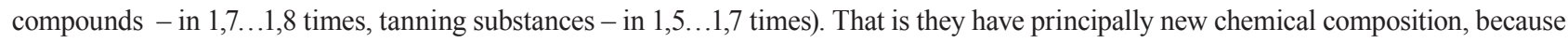
practically all bioactive substances (BAS) in cryopuree are in nanosize form and easily assimilated by human organism.

Keywords: deep processing, cryogenic freezing, fine-dispersed grinding, carotene-containing raw material, vegetable additives. 


\section{Introduction}

The global problem in international practice in many countries of the world is for today deficit of vitamins, $\beta$-carotene, mineral substances, proteins and other bioactive substances (BAS) in food allowance [1], and the need in them is incompletely satisfied. In this connection in many countries are many programs, within which many synthetic food products (milk, meat, vegetables, flour, peeled grains and so on) are created and already industrially produced. They almost do not differ from the natural ones by appearance and composition but are harmful for human organism. So, the functional health-improving products (especially, of fruits, berries and vegetables), containing significant quantity of vitamins, carotenoids and other BAS that favor the straightening of people immunity are very popular. Especially topical and prospective direction of receiving health-improving food products in different countries of the world (especially, in Japan, Germany and other) is the use of carotene-containing vegetables and berries (in particular, carrot, pumpkin, tomato, sweet pepper, apricot and other) for their preparation. They differ from other vegetable raw material by the high content of carotenoids and other BAS, especially phenol compounds with R-vitamin, anti-oxidative activity (rutin, hydroxycinnamic acids and other), polyphenol compounds. It is known, that unsaturated conjugated compounds of carotenoids and phenol compounds have anti-tumor, antiradiation, anti-oxidative effect and significantly increase human immunity. It is worth noting, that traditional ways of raw material processing lead to significant losses of carotenoids and other BAS (from 20 to $80 \%$ ). Today cryogenic freezing and cryogenic grinding are most progressive methods of the raw material processing in international practice. But they are not used in Ukraine for today and deficit of both frozen additives of traditional carotene-containing raw material and functional health-improving products of them is observed. The data, present in literature, have contradictive, incomplete character. It is urgent to elaborate principally new cryogenic method of deep processing of carotene-containing raw material using cryogenic "shock" freezing on the low-temperature program freezer as innovation.

The aim of the work is elaboration of principally new cryogenic method of deep processing of carotene-containing vegetable raw material (carrot, pumpkin, sweet Bulgarian pepper, tomato, sea buckthorn, apricot) and receiving of additives in nanosize form and high content of $\beta$-carotene and other BAS. At that the complex effect of cryogenic "shock" freezing and fine-dispersed grinding with new generation of modern equipment such as cryogenic program freezer (invention of M. E. Zhukovskiy national aerospace university "Kharkiv aviation institute" (Kharkiv, Ukraine) and low-temperature activator-grinder (France) is used as innovation.

This method is based on the process of cryomechanodestruction - non-enzyme catalysis-mechanolysis that leads to the destruction of biopolymer-BAS nanocomplexes that contain bioactive substances, especially, $\beta$-carotene in hidden form. Cryogenic processing of vegetable raw material gives a possibility to receive product in nanosize form. This method allows not only maximally preserve but more full open and use biological potential of vegetable raw material and transform BAS and biopolymers from the bound state in nanoform.

\section{Materials and methods of the study of content of $\beta$-carotene and other BAS and biopoly- mers at elaboration of new cryogenic method of deep processing of carotene-containing veg- etable raw material}

The study was carried out in Kharkiv state university of food technology and trade at the department of Technology processing of fruits, vegetables and milk (city Kharkiv, Ukraine).

Cryogenic "shock" freezing was carried out using the modern experimental equipment, especially cryogenic program freezer [2, 3, 4] (Fig. 1).

As the object of research there were used carotene-containing vegetables, fruits and berries, especially, carrot, pumpkin, sweet pepper, tomato, sea buckthorn and also frozen cryopuree and products on their base (nanojuices, jelly, nanosorbets) (Fig. 2).

The ripe carotene-containing vegetables were used: carrot of varieties "Nant 4", "Nant Kharkiv", "Paris carotel 443" and "Shantane 2461"; pumpkins of varieties "Vitamin" and "Mace"; tomato of varieties "Torch", "Moldavian early", "Erliston" and other; sweet Bulgarian pepper of varieties "Poltava", "Mulato" and "Rotunda". Along with it the early ripe varieties of apricots and sea buckthorn were used. 


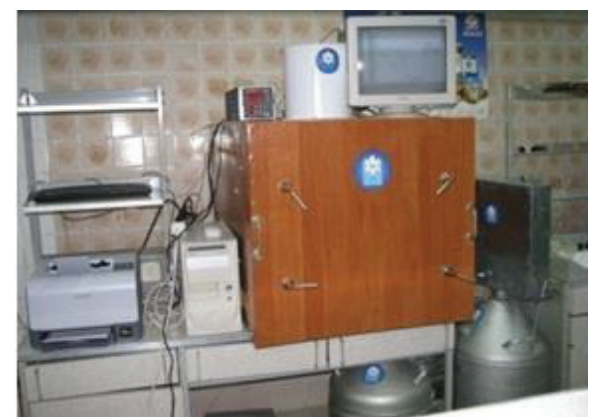

Fig. 1. Cryogenic program freezer

The preparation of samples for the study of cryogenic processing of raw material (freezing) and fine-dispersed grinding was carried out as following.

Carrot, pumpkin, sweet pepper and tomato were cut in pieces with width $0,5 \ldots 1,0 \mathrm{~cm}$ and length $4 \ldots .5 \mathrm{~cm}$, then put in plates for further freezing. Berries were frozen wholly, without grinding.

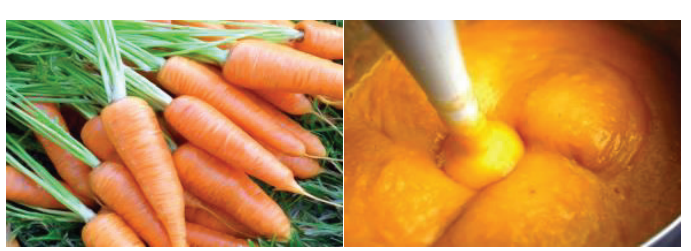

$a$

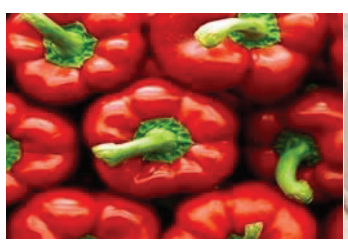

$e$

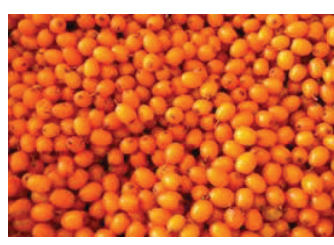

$i$

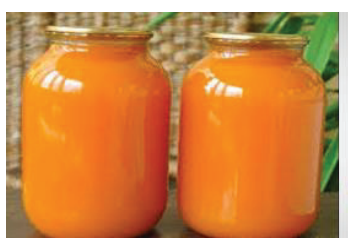

n $b$

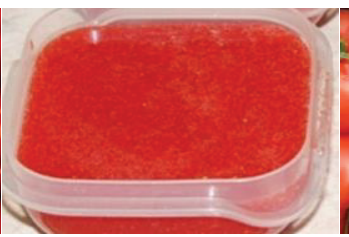

$f$

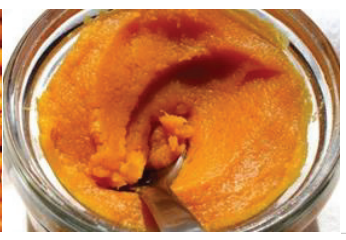

$k$

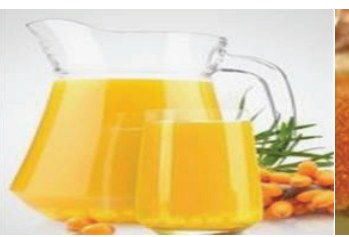

o

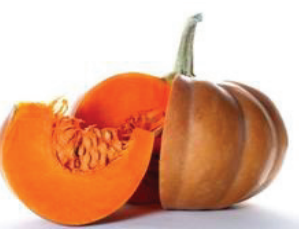

c

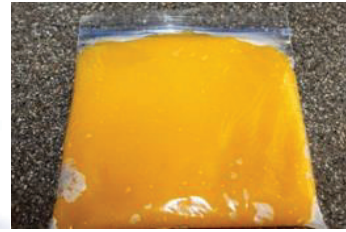

$d$

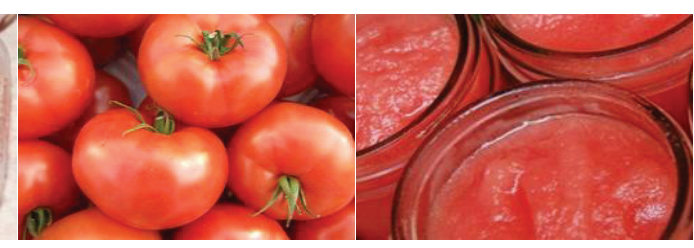

$g$

$h$

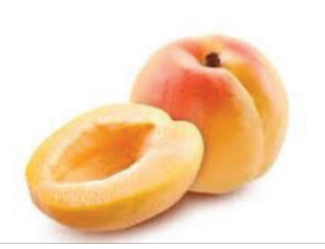

l

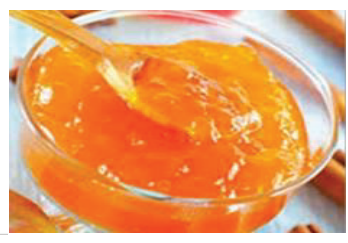

$m$

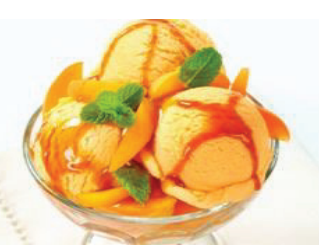

$r$

Fig. 2. Objects of research: $a$ - carrot; $b$ - cryopuree of carrot; $c$-pumpkin; $d$ - cryopuree of pumpkin; $e$-sweet pepper; $f$-cryopuree of sweet pepper; $g$ - tomato; $h$ - cryopuree of tomato;

$i$ - sea buckthorn; $k$ - cryopuree of sea buckthorn; $l$-apricot; $m$ - cryopuree of apricots; $n$, $o$ - carotinoid nanojuices; $p$ - carotinoid jelly; $r$ - carotenoid nanosorbets

Cryogenic processing of carrot-containing vegetable raw material was carried out at temperature $-60^{\circ} \mathrm{C}$ in speed-freezing chamber. The samples of raw material were frozen with different 
speed $\left(0,1 ; 0,2 ; 0,5 ; 2 ; 5 ; 10 ; 20^{\circ} \mathrm{C} / \mathrm{min}\right.$.) to the lower temperatures in product $\left(-35 \ldots-40^{\circ} \mathrm{C}\right)$, than at traditional freezing $\left(-18^{\circ} \mathrm{C}\right)$ using liquid and gasiform nitrogen. The final temperature of freezing was chosen based on the results, had been received earlier [2]. At that for freezing $1 \mathrm{~kg}$ of raw material were consumed from 0,5 to 1,01 of liquid nitrogen, depending on width of frozen samples. The volume of freezing chamber after raw material loading was up to $10 \mathrm{~kg}$. At freezing the mass share of carotinoids of carotene-containing vegetable raw material (carrot, pumpkin, tomato, sweet pepper, apricot, sea buckthorn) and also L-ascorbic acid were controlled. The last one is a criterion of assessment of freezing product quality.

The grinding of carotene-containing vegetable raw material was carried out in the low-temperature activator-grinder at temperature $-10 \ldots-15{ }^{\circ} \mathrm{C}$ that gave a possibility to receive products in nanosize form.

The preparation of samples, freezing and grinding were carried out using gasiform nitrogen on cryogenic program freezer, fine-dispersed grinder and other equipment. The methodology of samples processing is presented more detail in the works [2-4].

The temperature in freezing chamber was $-60{ }^{\circ} \mathrm{C}$. Cryogenic freezing was carried out using cryogenic program freezer (semi-productive speed-freezing tunnel apparatus), elaborated and created together by the specialists of M. E. Zhukovskiy national aerospace university "Kharkiv aviation institute" (Kharkiv, Ukraine) and Kharkiv state university of food technology and trade (Kharkiv, Ukraine). At the same time the influence of low-temperature fine-dispersed grinding of frozen vegetables, fruits and berries on carotenoids and ascorbic acid of CCVRM was studied. The grinding of frozen vegetables was carried out on the low-temperature activator-grinder at temperature $-10 \ldots-15^{\circ} \mathrm{C}$. Temperature modes were grounded earlier by the authors [2].

\section{1. Experimental procedures}

At realization of set tasks experimental studies were carried out fivefold using conventional standard methods of research. The received results are given in units of international system SI.

The content of $\beta$-carotene was controlled by colorimetric method of Muri after removal of carotene from the product by organic dissolvent and cleaning of carotene from attending color substances using column chromatography [5].

The content of L-ascorbic acid was determined by the method of visual and potentiometric titration by the solution of $\mathrm{Na}$ 2,6-dichlorophenollindophenol [6].

The content of phenol substances was determined by colorimetric method of Folin-Denis in recalculation by chlorogenic acid [7].

The content of polyphenols (tanning substances) determined by titrometric method in recalculation for tannin [8]. This method is based on the property of tanning substances to oxidize in presence of indigo carmine indicator.

The methodology of determination of indices ( $\beta$-carotene, L-ascorbic acid, phenol substances, polyphenols) of studied samples, namely carrot, pumpkin, sweet pepper, tomato, apricot, sea buckthorn and cryopuree of them and also carotenoid nanojuices, jelly and nanosorbets can be found in the work [9].

\section{Results}

The regularities of growth and transformation of carotene-containing raw material at cryogenic freezing with low-temperature grinding of frozen raw material were established. It was demonstrated, that at cryogenic freezing takes place the quantitative increase of mass share of carotenoids that depending on freezing speed and type of carotene-containing raw material is 2,0...2,5 times more comparing with initial raw material (fresh vegetables and berries) [4]. So, it was demonstrated, that frozen carotene-containing fruits, vegetables and berries contain $2,0 \ldots 2,5$ times more carotene than initial raw material. It was established, that at low-temperature grinding of cryogenically frozen CCVRM at receiving cryopuree takes place even more essential increase of carotenoids mass share that depending on CCVRM type in 3...3,5 times. Mass share of carotenoids (CR) that are in water-soluble form (WF) increases in parallel that is activation of 
hydrophilic properties of CR takes place. The ratio between fat-soluble (FF) and WF of carotenoids in frozen product is: 1:1 (at slow speed of freezing) and 1:1,5...1,7 (at cryogenic freezing and low-temperature grinding).

The mechanism of the raw material cryoprocessing that can explain the effect of increase and transformation of carotenoids in hydrophilic form at freezing was revealed (Fig. 3). At cryogenic freezing at crystal-creation takes place the destruction of carotenoids nanocomplexes with biopolymers (protein, cellulose, pectin substances, farina) and transfer of part of carotenoids from the form, bound with biopolymers, to the free one at the expanse of destruction of hydrogen connections, weakening of inductive interaction and so on.

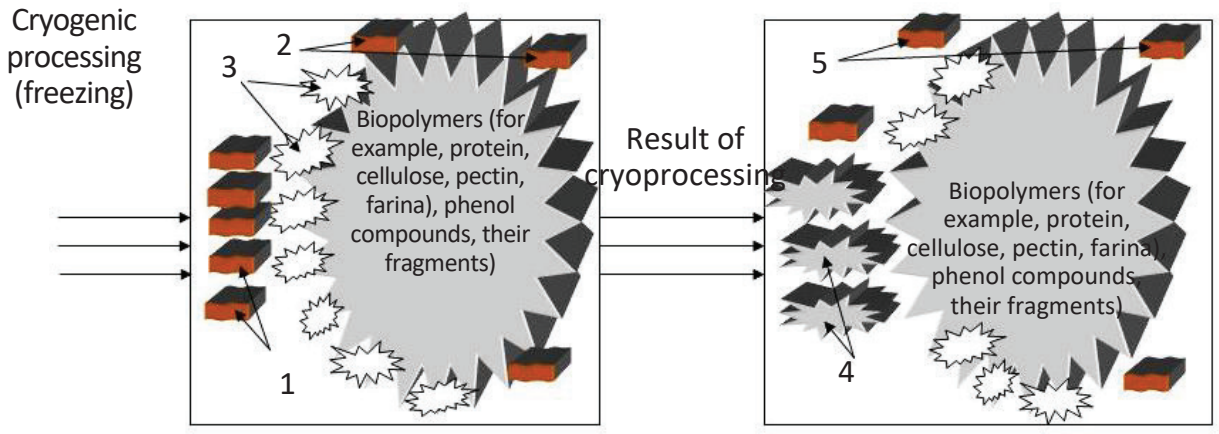

Fig. 3. Schematic presentation of mechanism of influence of cryoprocessing of carotene-containing vegetables, fruits and berries on preservation and creation of new water-soluble forms of carotenoids: 1 - CR infree form; 2 - CR bound with biopolymers;

3 - hydrophilic groups of fragments of biopolymers, phenol compounds; 4 - water-soluble complexes of carotenoids (CR-protein, CR-cellulose, CR-pectin, CR-phenol compounds and other); 5 - CR that transferred into free state from the one, bound with biopolymers

The water-soluble forms of CR are understood as water-soluble complexes (associates) of CR with biopolymers (of protein, cellulose, pectin, farina and other), phenol compounds or their fragments that have hydrophilic properties at the expense of hydrophilic groups $\left(\mathrm{NH}_{2}^{-}, \mathrm{SH}^{-}, \mathrm{OH}^{-}, \mathrm{COH}^{-}\right.$, $\mathrm{CH}^{-}$), contained in them. Along with it at freezing can take place the creation of water-soluble forms of $\mathrm{CR}$ at the expanse of creation of complexes between CR and biopolymers (of protein, carbohydrates and other), phenol compounds and their fragments that have hydrophilic properties (Fig. 3).

The received experimental data allow present in the modern way the influence of processes of cryogenic freezing and low-temperature grinding at processing of carotene-containing raw material into carotenes and activation of their hydrophilic properties. The mechanism of influence of processes of cryogenic freezing and low-temperature grinding at processing of carotene-containing raw material is in cryodestruction of nanocomplexes of carotenoids with biopolymers, destruction, mechanocracking of connections between BAS and biopolymers that leads to increase of carotenoids mass share (in 1,5...2,5 times depending on freezing speed and in 3, 0...3,5 times at low-temperature grinding) and also activation of their hydrophilic properties - transformation of part $(50 . . .70 \%)$ of carotenoid in water-soluble form $[10,11]$.

Technological modes such as cryogenic freezing and low-temperature grinding at processing of carotene-containing vegetable raw material were used at scientific grounding of nanotechnology of frozen carotenoid additives - coloring agents - enricher with carotenoids, the half of which is in water-soluble form.

The comparative characteristic of $\beta$-carotene and other BAS content in fresh and cryofrozen carotene-containing vegetable products with high speed of freezing and nanostructured puree of them is presented below (Table 1).

The cryopuree, received of carotene-containing vegetable raw material have principally new chemical composition than puree, received by the traditional technologies. It was demonstrated, that the received cryopuree essentially exceeds initial raw material by BAS content: by $\beta$-carotene content - in 3-3,5 times, L-ascorbic acid - in 2-2,2 times, phenol substances - in 
1,7-1,8 times, tanning substances - in 1,5-1,7 times (Table 1). It was demonstrated, that practically all BAS in cryopuree are in nanosize, easily assimilated form. It is known, that the size of molecules of aforesaid BAS in additives, received of CCVR is in diapason from 0,5 to 1,5 nm [1]. $100 \mathrm{~g}$ of cryopuree of carrot, pumpkin, sea buckthorn, apricot include $5 \ldots 6$ day norms of $\beta$-carotene for human organism. Along with it their content of ascorbic acid is from $1 / 4$ to 1 day norm for human organism that is $70-100 \mathrm{mg}[1]$.

Table 1

The comparative characteristic of $\beta$-carotene and other BAS content in fresh and cryofrozen carotene-containing vegetables, fruits and berries with high speed of freezing and nanostructured puree of them

\begin{tabular}{|c|c|c|c|c|}
\hline \multirow[b]{2}{*}{ Product } & \multicolumn{4}{|c|}{ Mass share (mg in $100 \mathrm{~g})$} \\
\hline & $\beta$-carotene & L-ascorbic acid & $\begin{array}{l}\text { Phenol compounds } \\
\text { (for chlorogenic acid) }\end{array}$ & $\begin{array}{l}\text { Flavonol glycosides } \\
\text { (for rutin) }\end{array}$ \\
\hline Fresh carrot & $9,8 \pm 0,3$ & $10,5 \pm 0,2$ & $154 \pm 12,1$ & $60,2 \pm 3,6$ \\
\hline Carrot, frozen in pieces & $20,4 \pm 1,2$ & $20,0 \pm 1,5$ & $205 \pm 4,8$ & $90,3 \pm 6,2$ \\
\hline Nanostructured puree of carrot & $30,2 \pm 2,5$ & $28,6 \pm 1,8$ & $290 \pm 6,9$ & $110,3 \pm 5,8$ \\
\hline Fresh pumpkin & $10,2 \pm 0,4$ & $14,2 \pm 0,3$ & $143 \pm 11,8$ & $52,0 \pm 4,0$ \\
\hline Pumpkin frozen in pieces & $21,0 \pm 1,0$ & $25,3 \pm 0,5$ & $200 \pm 10,5$ & $70,2 \pm 3,8$ \\
\hline Nanostructured puree of pumpkin & $35,5 \pm 2,8$ & $34,8 \pm 2,4$ & $250 \pm 12,6$ & $85,6 \pm 5,2$ \\
\hline Fresh apricot & $8,5 \pm 1,6$ & $40,2 \pm 1,8$ & $120,3 \pm 10,1$ & $45,4 \pm 1,2$ \\
\hline Frozen apricot & $15,2 \pm 1,0$ & $60,5 \pm 5,0$ & $150,4 \pm 8,2$ & $70,2 \pm 5,1$ \\
\hline Nanostructured puree of apricot & $24,2 \pm 2,2$ & $120,3 \pm 10,4$ & $180,5 \pm 12,1$ & $80,3 \pm 3,9$ \\
\hline Fresh sea buckthorn & $12,8 \pm 0,6$ & $70,2 \pm 5,4$ & $160,2 \pm 12,1$ & $70,2 \pm 5,4$ \\
\hline Frozen sea buckthorn & $18,9 \pm 1,2$ & $100,4 \pm 10,2$ & $203,3 \pm 20,2$ & $100,1 \pm 10,2$ \\
\hline Nanostructured puree of sea buckthorn & $36,8 \pm 2,8$ & $215,3 \pm 11,2$ & $240,2 \pm 25,4$ & $125,2 \pm 11,6$ \\
\hline Fresh tomato & $7,0 \pm 0,4$ & $25,4 \pm 1,2$ & $125,4 \pm 8,2$ & $55,2 \pm 1,8$ \\
\hline Nanostructured puree of tomato & $20,0 \pm 1,9$ & $50,2 \pm 5,6$ & $260,2 \pm 24,8$ & $90,7 \pm 15,1$ \\
\hline Fresh sweet Bulgarian pepper & $5,5 \pm 0,1$ & $200,4 \pm 20,4$ & $148,2 \pm 20,4$ & $85,2 \pm 5,8$ \\
\hline sweet Bulgarian pepper frozen in pieces & $10,6 \pm 0,5$ & $300,0 \pm 30,6$ & $190,2 \pm 18,0$ & $120,3 \pm 7,2$ \\
\hline $\begin{array}{l}\text { Nanostructured puree of } \\
\text { sweet Bulgarian pepper }\end{array}$ & $16,9 \pm 1,8$ & $401,2 \pm 39,6$ & $250,6 \pm 25,6$ & $145,8 \pm 10,3$ \\
\hline
\end{tabular}

\section{Conclusions}

The principally new method of cryogenic processing of carotene-containing raw material was elaborated. It was established, that the use of new method of deep processing of carotene-containing raw material (cryogenic "shock" freezing and fine-dispersed grinding) allows receive qualitatively new additives in form of frozen nanopuree of carotene-containing vegetables and berries (carrot, pumpkin, sweet Bulgarian pepper, tomato, apricot, sea buckthorn) with record content of BAS in easily assimilated form that are impossible to be received by traditional methods. According to chemical composition, new additives of carotene-containing raw material have potential immune modeling, anti-tumor, detoxing effect. These conclusions were proved by the tests in Institute of medical radiology named after S. P. Grigoriev, NAMS of Ukraine [12].

The received experimental data, presented in the article, were a base at elaboration of cryogenic nanotechnology of CCVRM as frozen nanopuree and nanopowders of sublimation drying. New technologies were probated in industrial conditions in SIE "CRYAS" (Kharkiv, Ukraine) and the normative documentation was elaborated (TCU 15.3-01566330-306 and TI). On their base were elaborated the new types of health-improving products (carotinoid health-improving muffins for schoolchildren and biscuits, introduced in production at MI "Industrial complex of child food" (Kharkiv, Ukraine).

There were also elaborated thermostable carotenoid fillings for confectionery, introduced in production at SIF "KPC" (Kharkiv). On the base of carotenoid additives were also elaborated the health-improving products: nanosorbets, cheese desserts, nanojuices, nanodrinks, creams, biokefirs, bioyogurts and other for food enterprises and for ones of restaurant business and trade. 
The development and continuation of the research in this direction is the study of influence of processes, considered in the work, on hardly-soluble nanocomplexes of biopolymers (pectin substances, cellulose). At the same time the widening of assortment of natural product in nanoform with high BAS content.

\section{References}

[1] Tutel'ian, V. A., Vialkov, A. I., Razumov, A. N., Mihailov, V. I., Moskalenko, K. A., Odinets, A. G., Sbezhneva, V. G., Sergeev, V. N. (2010). Nauchnye osnovy zdorovogo pitaniia. Moscow: Panorama, 816.

[2] Pavlyuk, R., Pogarskaya, V., Pavlyuk, V., Radchenko, L., Yur'eva, O., Maksimova, N. (2015). Cryo- and Mechanochemistry in the food technology. Kharkiv: Fact, 255.

[3] Pavlyuk, R., Pogarska, V., Balabai, K., Pavlyuk, V., Kotuyk, T. (2016). The effect of cryomechanodestruction on activation of heteropolysaccaride-protein nanocomplexes when developing nanotechnologies of plant supplements. Eastern-European Journal of Enterprise Technologies, 4 (11 (82)), 20-28. doi: 10.15587/1729-4061.2016.76107

[4] Pavlyuk, R., Pogarska, V., Pavlyuk, V., Balabai, K., Loseva, S. (2016). The development of cryogenic method of deep treatment of inulin-containing vegetables (topinambour) and obtaining of prebiotics in the nanopowders form. Eureka: Life Sciences, 3, 36-43. doi: 10.21303/2504-5695.2016.00145

[5] Pavlyuk, R., Pogarska, V., Radchenko, L., Roman, D. T., Timofeyeva, N., Kotuyk, T. (2016). The new method of processing of carotene-containing vegetables for the production of nanoproducts using combi-steamers and fine-dispersed comminution. Eureka: Life Sciences, 3, 44-49. doi: 10.21303/25045695.2016 .00146

[6] DSTU 4305:2004. Fruit, vegetables and products of their processing. Method of determination of carotin (2005). Kyiv: DP «UkrNDNC», 18.

[7] GOST 24556-89. Mezhgosudarstvennyy standard. Products of processing of fruit and vegetables. Method of determination of vitamin C (2003). Moscow: IPK publishing house of standards, 12.

[8] GOST 24027.2-80. Raw medicinal plant. Methods for determination of moisture, ash, extractives and tannins, essential oil (1980). Moscow: Publishing House of Standards, 24.

[9] Pavlyuk, R., Pogarska, V., Radchenko, L., Tauber, R. D., Timofeyeva, N. (2016). Deep processing of carotene-containing vegetables and obtaining nanofood with the use of equipment of new generation. Eastern-European Journal of Enterprise Technologies, 4 (11 (82)), 36-43. doi: 10.15587/1729-4061.2016.76232

[10] Pogarskaia, V. V., Pavlyuk, R. Iu., Cherevko, A. I., Pavlyuk, V. A., Maksimova, N. F. (2013). Aktivatsiia gidrofil'nyh svoistv karotinoidov rastitel'nogo syr'ia. Kharkiv, 345. 